\title{
The Natural Rate of Interest and the Optimal Rate of Interest in the Steady State
}

\begin{abstract}
The "natural rate of interest" is the hypothetical, risk-free real rate of interest that would obtain in a closed economy, if net public debt were zero. It is considerably less than the optimal steady-state rate of interest, which is equal to the system's growth rate. This holds for a very general "meta-model." The fundamental equation of capital theory holds on the optimal steady-state path: $T=Z-D$, where $T$ is the overall economic period of production, $Z$ is the representative private "waiting period" of consumers and $D$ is the public debt ratio. Prosperity is at least $30 \%$ lower at the natural rate of interest than at the optimal rate.
\end{abstract}

\subsection{Definition of the Natural Rate of Interest}

The term "natural rate of interest" goes back to Knut Wicksell (Wicksell [1898]). In his important book Interest and Prices, Wicksell identified the function that a central bank is supposed to fulfill by way of its interest rate policy. He compared the interest rate set or at least influenced by the central bank to the "natural rate of interest." The latter is the interest rate that the central bank should strive to achieve, since at it there is a threat neither of inflation nor of deflation. If the central bank sets the interest rate below the natural rate, there is a threat of inflation. If it sets the interest rate above the natural rate, there is a threat of deflation. The natural rate of interest is thus also the dividing line between those interest rates at which a self-reinforcing process of inflation is set into motion and those rates at which a self-reinforcing process of deflation is to be expected.

A different problem is the focus of our analysis. The short-term macroeconomic management of the economy using the central bank's monetary policy is not our primary concern. Our concern is rather the question of whether public debt is required in the 21 st century, if we want to combine price stability and full

C. C. von Weizsäcker and H. M. Krämer, Saving and Investment

in the Twenty-First Century, https://doi.org/10.1007/978-3-030-75031-2_2 
employment. Hence, for analytical purposes, we are interested in the question of how high the real full employment interest rate would be, if there were no public debt. This is the interest rate that we call the "natural rate."

We are thus posing the same question that Eugen von Böhm-Bawerk already raised in the second volume of his Capital and Interest: The Positive Theory of Capital (Böhm-Bawerk [1889]). His answer was that this natural rate of interest is positive. And we suspect that his answer was empirically correct for his time. Although there was also a great deal of public debt back then, he was not principally interested in explaining the current level of the interest rate. He wanted to explain the phenomenon of interest as such. For this purpose, it was necessary to exclude the state as a participant in the capital market. Just as, at around the same time, Léon Walras and, later, his followers, all the way up to Arrow and Debreu, analyzed general equilibrium and its Pareto optimality using a model without government influence on markets, in the same way, Böhm-Bawerk wanted to explain interest as part of a general equilibrium in which the state plays no role. What was important for him was understanding interest as a scarcity price (for scarce capital). His book was thus the response of "bourgeois economics" to the exploitation theory of profit that Karl Marx had developed in the first volume of Capital (Marx 1976 [1867]).

We will come back to Marx and Böhm-Bawerk in the first part of Chap. 4 on real capital. In particular, we will closely examine Böhm-Bawerk's "law of the greater productivity of more roundabout production.” For Böhm-Bawerk, this law was one of the three reasons why the real rate of interest is positive in a stationary general equilibrium.

Böhm-Bawerk's model was a model of a stationary closed economy. Generalizing Böhm-Bawerk, we nowadays argue within the framework of a model of a closed economy that is growing at a constant rate.

Definition For us, the natural rate of interest is the risk-free, real rate of interest that is compatible with full employment in a closed economy without public debt that is growing at a constant rate.

The natural rate of interest defined in this way is the reference point from which we consider the current global economic landscape. The latter, of course, includes a high level of net public debt. We can presume that the real full-employment equilibrium rate of interest is higher with this public debt than the "natural rate" as we have defined it. Following more recent terminology (cf., for example, Rachel and Summers 2019), what Wicksell meant by the "natural" rate of interest, we call rather the neutral rate. We will come back to the neutral rate in Sect. 7.6. 


\subsection{Profit, Risk, Interest and Overall Economic Returns}

The lending business is sometimes not without risk for the lender. Hence, professional providers of loans-like, for example, banks - will demand a premium on the interest rate, which, from the point of view of the lender, represents adequate compensation for the risk assumed. The "spread" that a country like Italy has to pay on the capital market as compared to German government bonds is an example of this risk-based premium, which is thus also described as a risk premium. Interest rates that are high because the capital market assesses the borrower's risk of nonpayment as high are obviously not a good indicator of the internal rate of return of the financed investment project for the economy as a whole. This applies for private and public borrowers alike. If we want to use interest rates to draw conclusions about the marginal social productivity of investments, then we have to use interest rates that have been cleansed of this risk premium.

Banks and other businesses that are routinely involved in making loans devote considerable resources - in particular, human resources - to selecting those borrowers who are "creditworthy" or, in other words, with whom the lender can expect to do "good business." If competition between lenders functions properly, then ideally it should bring interest margins down to the point at which the risk premium of the bank for the last successful loan-seeker is just sufficient to cover the risk assumed in providing the loan. The expenses incurred by the bank in selecting "creditworthy" borrowers must, however, be taken into account in this calculation. We can thus propose the following formula as an equilibrium condition for a competitive credit market: "Interest margin = pro-rata selection expenses + provisions for default in the case of the last successful loan-seeker." Thus, the bank does not earn anything more on the last successful loan-seeker.

In practice, this purely formal presentation is rendered more complicated by, among other things, the fact that the default risks of individual borrowers are positively correlated for reasons relating both to the overall economic climate and to industry-specific risks. As consequence, lenders often work with consolidated risk assessments and consolidated provisions for default. Some part of the selection expenses, moreover, cannot be assigned to individual loan applications either. The loan officers have to acquire know-how and experience. Research has to be done on industry-wide developments or political developments. Hence, consolidated values are also used to a considerable extent in the calculation of selection expenses. This use of consolidated values also means that price differentiation (in this case, interest margin differentiation) between individual borrowers is not perfect. As a result, the "price" (in this case, the interest margin) is, as it were, above the "marginal cost" for the lender of dealing with the individual borrower, but, on the other hand, "fixed costs" of lending are also created, which must, so to say, be "passed on" to all borrowers if the bank does not want to incur losses.

The lending business of banks can be best represented using the model of monopolistic competition or, alternatively, using a model of heterogeneous oligopolistic competition. In the case of monopolistic competition, suppliers do not 
generate any profits beyond a risk premium for the capital employed. For, ultimately, there are not any significant barriers to entry for the lending business. In modern financial markets, there is an interbank money market, which always allows solvent banks to obtain the resources required for extending loans. Profits that are above-average as compared to other industries are thus eliminated by the competition of both new market entrants and the expanded business of banks that were already present in the market. On average, the marginal borrower thus gives rise to additional costs for the lending bank that, including appropriate (and possibly consolidated) risk provisions, exactly correspond to the interest margin.

Of course, this statement is only valid "on average," since, depending on the current economic climate, there are times when banks can extend more loans than usual without a proportionate increase in short-term expenditure - and there are times when lending is less than usual, such that it is not possible fully to cover the costs that, in the short term, are to be regarded as fixed.

This on-average statement about the marginal borrower means that the overall economic return on the investment that he or she makes with the loan is not greater than the risk-free market rate of interest. This can be seen most clearly in the case of the government bonds of countries that are regarded as absolutely no-risk borrowers. For, so long as the circulation of the tradable debt of this borrower ensures sufficient liquidity, the opportunity costs of the bank in using money to extend loans are derived from the use of this money to buy government bonds. The lender calculates an expected return on the investment for the marginal borrower that is based on the interest that the borrower has to pay to the bank. If the return expected by the lender were greater than this interest, then the borrower would not in fact be the marginal borrower, but rather an inframarginal borrower. The interest margin that the marginal borrower has to pay corresponds to the costs to which he or she gives rise, on average, for the bank. If we subtract these costs-which are also costs for the economy as a whole - from the expected profit of the borrower, then what remains is an expected overall economic return that is exactly equal to the risk-free interest rate.

What applies for the private borrower, also applies for the public borrower from whom the capital market demands a risk premium. If government bonds are traded with a yield that is greater than the yield of the most secure government debt, then the same causes determine the lender's costs as in the case of the bank loan discussed previously. The yield of the bond of a private issuer reflects the average risk assessment of its current and potential creditors. If there were a large number of potential buyers who do not see any risk in the bond, then it would be traded with a yield corresponding to the risk-free interest rate. If the bond is seen as a risk by the investors, then, at the margin, these investors are indifferent between a small increase in the holdings of this bond in their portfolios and additional holdings of risk-free bonds. For the economy as a whole, this means that the ex-ante value of a small additional investment with the one borrower is equal to the ex-ante value of a small additional investment with the other borrower. It is thus clear that despite the higher yield (due to the risk premium) of the bond of the private borrower, the 
additional investment of the latter is not ex-ante worth more for the economy as a whole than that of the risk-free borrower.

This conclusion is not invalidated by the liquidity argument. The difference in yield between private bonds and government bonds that are regarded as absolutely risk-free is sometimes also explained by the different liquidity of the securities in question. However correct this explanation is, it is important to understand that this liquidity premium is a special case of a risk premium. But the risk now lies not with the borrower, but rather with the lender, whose own future liquidity requirements cannot be foreseen with certainty. Hence, the lender demands compensation in the form of additional yield for an investment that is relatively illiquid.

The profit of the "Schumpeterian" innovative entrepreneur (Schumpeter 1934 [1911]) is an example of what is known as entrepreneurial profit in economic theory. We all know how essential innovations are for economic progress. But every innovation is tied to risks, and the profit or loss resulting from it cannot be exactly estimated in advance. Innovations have usually to be financed with equity. If we follow the Schumpeterian theory, according to which the activity of risk-taking innovators is the basis of economic progress, then attempted innovations create, on average, a social return that is greater than their costs. As a rule, this social return on innovation is not entirely eliminated by competition, since innovations give rise, on average, to positive externalities. But successful innovations usually attract imitators, such that in the long run, albeit with a certain delay, the entrepreneurial profits of innovation can be eliminated by competition. The fact that there are such innovations with their associated positive externalities does not, however, contradict our conclusion that the risk-free interest rate is the correct price signal for the marginal return on investment for the economy as a whole. We have to distinguish between the economically useful willingness of entrepreneurs to take risks and the marginal return on the capital involved. As concerns the latter, there is no systematic reason why lower interest rates should lead to more Schumpeterian innovation.

There is no consensus among economists on this point. Lower interest rates may well facilitate the financing of new projects. But, on the other hand, very low interest rates can, on the view of some economists, contribute to preserving "zombie firms," which tie up resources - especially human resources - in activities that are scarcely productive for the economy as a whole, thus making it more difficult for Schumpeterian entrepreneurs to carry out their innovative experiments. Similarly, the incentive to undertake productive changes may diminish, if a kind of "zombie full employment" is preserved by way of low interest rates. The Japan specialist Gunther Schnabl is an eloquent proponent of this last thesis (cf. Schnabl 2019).

We will refrain from taking sides in this debate here. Our view is thus that when comparing steady states, the interest rate level is neutral with respect to the intensity of Schumpeterian innovation. This is, however, an agnostic position with regard to the question. We thus stand by the conclusion that the risk-free interest rate on public debt is the correct price signal for the intertemporal trade-off between consumption at different points in time. In Sect. 2.10, we will consider the case when 
the risk-free interest rate on public debt does not correspond to the intertemporal trade-off between consumption at different points in time.

\subsection{Capital-Theoretical Foundations}

We will now work with the following assumption, which is grounded in capital theory.

Assumption 1 A. In a closed economy, there is exactly one natural rate of interest. B. A risk-free, steady-state interest rate above the natural rate is connected to positive net public debt. A risk-free, steady-state interest rate below the natural rate is connected to negative net public debt.

In Carl Christian von Weizsäcker's "Capital Theory of the Steady State”, this premise is derived from certain price-theoretical assumptions: in particular, from the Law of Demand (Weizsäcker 2021; cf. Theorem 4). But here we can already refer to the following intuition: In a growing closed economy, we expect there to be a lower equilibrium rate of interest at a higher saving rate. A higher steady-state public debt ratio in a growing economy means that public debt is rising in absolute terms and that thus, with given private saving behavior, the saving rate is lower than it would be without this higher steady-state public debt. We therefore expect a higher risk-free equilibrium rate of interest.

\subsection{The Generalized Golden Rule of Accumulation}

The macroeconomic production function of the Solow Model is often used in the macroeconomic literature. Solow first presented his model in 1956 and then provided an empirical supplement to it in 1957 (Solow 1956, 1957). Within the framework of this model, in 1961, Phelps and von Weizsäcker, independently from one another, developed a theory of the optimal steady-state rate of interest, which became known under the name coined by Phelps: the "Golden Rule of Accumulation" (Phelps 1961; von Weizsäcker 1961 and 1962). It turns out that the theoretical derivation of the natural rate of interest becomes much clearer and more accessible, once it is understood that the well-known "Golden Rule of Accumulation" can be generalized far beyond the Solow Model. This generalized Golden Rule of Accumulation produces a reference point in the form of an interest rate $r=g$, where $g$ is the growth rate of the system. We can then compare the natural rate of interest $\rho$ with this reference point. This gives rise to insights that are useful for further empirical analysis. 
Before beginning with the formal analysis, a word about our chosen unit of measurement. The flow variables employed, like total product or total wage payments, and the stock variables, like real capital, are conceived as nominal values. Thus, for example, the total net national product as measured in euros per year, is divided by the number of labor years performed annually, to yield annual net output per labor year $y$. Or the real capital stock of the economy, as measured in euros, is divided by the number of labor years performed annually to yield the capital stock per labor year, $v$. Needless to say, we are ultimately interested in inflation-adjusted "real" quantities. Nonetheless, we are conscious of the fact that no unambiguous answer can be given to the question of how great real growth is on the long-term average. In the real world, the basket of goods consumed is constantly changing: not only proportionally, but also due to differing growth rates of its components, as well as the addition of new components or the complete disappearance of old ones. The resulting lack of clarity in measuring real growth over longer periods of time is well known to statisticians under the heading of the "index number problem." If we work with nominal quantities, however, we can circumvent these hazards within the framework of a steady-state analysis, by assuming that the nominal total product grows at a given rate $g$ per year that remains constant over time. It is possible that structural change lies behind this nominal growth rate. But we have no need to take this structural change into consideration in this chapter. We can, of course, choose the growth rate $g$ in such a way that it corresponds to a constant price level in the short term. It would then represent a good short-term to medium-term approximation of the real growth rate.

The interest rate $r$ with which we will be working in the following analysis is likewise the nominal rate of interest. If, however, the growth rate of the system is chosen in such a way that the price level remains constant in the short term, then $r$ is also the real rate of interest.

We now begin the formal analysis. We divide up the net product $y$ per labor unit (= a full labor year) as follows

$$
y=w(r ; \theta)+r v(r ; \theta)
$$

Here, $v$ is the value of the real capital employed per worker (= per labor year), $r$ is the risk-free rate of interest at which the government is able to borrow, and $\theta$ is the name of the production technique employed. We assume that $\theta$ is a function of $r$. We now introduce the following naming convention: $\theta(r)=r$. The variable $w(r$; $\theta$ ) is the "remainder" of the total product per labor year that is left over once we have subtracted the risk-free interest on the capital employed $r v(r ; \theta)$. The letter " $w$ " reminds us that ever since Böhm-Bawerk, and all the way up to the Cambridge versus Cambridge capital theory controversy of the 1960s and 1970s, this quantity has been identified in capital-theoretical models with a worker's yearly wage. But for us, $w$ represents far more than the wage. Thus, for example, it also includes risk premiums on the capital employed. Hence, $w$ should not be used for the purpose of distributional analyses. 
Nonetheless, the variable $w$ is "more fundamental" than the variable $y$. With a given real allocation and a given price level, nominal net output is dependent upon the rate of inflation. This phenomenon is well-known in macroeconomics. The same thing does not apply for the variable $w$, however, because the nominal interest rate moves in lockstep with the inflation rate. Hence, we also call $w$ the "net-net product" per labor year.

We use Theta to designate the set of production techniques that are employed at some given rate of interest in the steady state. We can thus write the following formula

$$
\text { Theta }=\{\theta: \exists r \text { st } \theta=\theta(r) \equiv r\} .
$$

The economic meaning of this definition of the set Theta is that we are limiting the comparison among production techniques to those techniques that will be used in a steady state. We are thus not looking for a production technique that is Pareto-optimal. The set Theta can contain many inefficiencies. The following assumption is thus not to be confused with the assumption of Pareto optimality. We will call it the Assumption of Steady-State Efficiency.

Assumption 2 Steady-State Efficiency 1: For every rate of interest $r$ and all $\theta \in$ Theta, $w(r ; \theta(r)) \geq w(r ; \theta)$ holds.

This means that the risk-free rate of interest is a correct price signal for the choice of the "right" production technique as a function of the interest rate, so long as this only concerns production techniques that are used at some steady-state rate $r$. The production technique will be chosen from the set Theta of techniques $\theta$ which have the property that there exists a rate of interest $r$, so that $\theta$ maximizes the surplus $w$ of the total product over the interest on the capital employed. It should be noted that an even stronger assumption was customary in the capital-theoretical literature.

Here, we will also briefly discuss this Assumption 2 as it relates to the literature on the theory of public debt. Pierre Yared has provided an overview of this literature in Yared (2019). The issue that he addresses is whether one of the different theoretical approaches can explain the secular growth of the public debt ratio. $\mathrm{He}$ divides the theoretical approaches into two groups: 1. optimal government debt policy, 2. political economy forces behind rising government debt. He is not convinced by explanations drawing on optimal government debt policy: According to Yared, neither tax smoothing nor safe asset provision nor the elimination of dynamic inefficiency can explain the secular trend of the public debt ratio. In connection with the approach of this book, we are particularly interested in his rejection of the argument that debt could serve to eliminate dynamic inefficiency. Yared does not regard there as being any dynamic inefficiency in reality: "However, 
there is no evidence of capital overaccumulation in the United States or advanced economies in the post World War II period (Abel, Mankiw, Summers and Zeckhauser 1989)." In a footnote, he adds: "Geerolf (2018) reaches the same result when applying the methodology of Abel, Mankiw, Summers, and Zeckhauser (1989) to more recent US data. Using a different methodology and data, however, this work finds less-strong evidence in favor of dynamic efficiency." But if we read Geerolf's paper (Geerolf 2018), its main finding is clearly that if the data is correctly interpreted, then dynamic inefficiency is present at least in two countries (Japan and South Korea), and that dynamic inefficiency cannot be ruled out in any OECD member state. The main reason for the discrepancy between this finding and earlier findings is the prior overestimation of the marginal productivity of capital, since returns were included in the rate of return on capital that in fact have nothing to do with the marginal productivity of capital. According to Geerolf, recently released OECD data allows these apparent rates of return on capital to be distinguished from the "real" rates. Our argument in Section 2.2 above is thus given empirical support, as is our Assumption 2 on Steady-State Efficiency. From the latter, we will derive below the conclusion that the risk-free rate of interest $r$ is a correct price signal for the marginal productivity of capital in the steady-state context.

In conjunction with the naming convention $\theta(r)=r$, it follows from the Steady-State Efficiency Assumption that for the partial derivative of $\theta(r)=r$ with respect to $\theta$, at $\theta=r$,

$$
\frac{\partial w(r ; \theta)}{\partial \theta}=0 \text { for } \theta=r
$$

holds.

Weizsäcker 2021, Chap. 2, Sect. 12 is a an extensive discussion of the basic assumption of the present chapter that the risk-free real rate of interest is a price signal for the steady state marginal productivity of capital.

Besides the division of the net product that we have introduced here, there is also the conventional division into consumption and investment

$$
y=c+\tilde{I}
$$

In this equation, $c$ is consumption per labor year and $\tilde{I}$ represents net investment per labor year. We now introduce a further assumption:

Assumption 3 The ratio between consumption per labor year, $c$, and the value of capital goods per labor year, $v$, remains constant over time for a given rate of interest. 
For reasons that will become clear later on, we depart from the usual definition of the capital coefficient and define the capital coefficient rather as the ratio $v / c$, whereby we always understand consumption $c$ here as steady-state consumption per labor year. Using this definition, we can also express Assumption 3 as follows:

Assumption 3 (alternative formulation): For a given interest rate, the capital coefficient remains constant over time.

We will later examine the case in which Assumption 3 does not hold, but rather the capital coefficient exhibits a trend at a given rate of interest.

Let $g$ designate the steady-state growth rate of the closed economy in question. Given Assumption 3, net investment per labor year in the steady state is then equal to $g v(r ; \theta)$. We thus have:

$$
y=c+g v(r ; \theta)
$$

In Weizsäcker (2021), Carl Christian von Weizsäcker shows why $c$ is only dependent on $\theta$, but not on $r$. Ultimately, this is due to the fact that in working with nominal values, we are free to define the price level of the different steady-state paths.

We thus get the equation

$$
c(\theta)+g v(r ; \theta)=w(r ; \theta)+r v(r ; \theta)
$$

We partially differentiate this equation with respect to $\theta$

$$
\frac{d c}{d \theta}+g \frac{\partial v}{\partial \theta}=\frac{\partial w}{\partial \theta}+r \frac{\partial v}{\partial \theta}
$$

At $\theta=r$, we previously derived

$$
\frac{\partial w(r ; \theta)}{\partial \theta}=0
$$

Hence, at $\theta=r$, the following holds

$$
\frac{d c}{d \theta}+g \frac{\partial v}{\partial \theta}=r \frac{\partial v}{\partial \theta}
$$

Let $\varphi$ be the "marginal productivity of capital": i.e., the change in total product resulting from a marginal change in $\theta$ divided by the marginal change in the value of capital, with prices being held constant or, in other words, with $r$ held constant. Hence, so long as $\partial v / \partial \theta \neq 0$, then 


$$
\varphi=\frac{d c / d \theta+g \partial v / \partial \theta}{\partial v / \partial \theta}=\frac{r \partial v / \partial \theta}{\partial v / \partial \theta}=r
$$

If $r$ is a correct price signal, then it is also a correct price signal for the marginal productivity of capital.

If there is a $\theta^{*}$ in Theta that leads to a level of consumption per labor year that is at least as high as the consumption per labor year of all other $\theta \in$ Theta, then the partial derivative of $c$ with respect to $\theta$ must be equal to zero at $\theta *$ : i.e.,

$$
\frac{d c}{d \theta}=0
$$

at $\theta=\theta^{*}$.

Moreover, on the assumption of steady-state efficiency, for every $r$ and the associated $\theta(r)=r$, the equation

$$
\frac{\partial w}{\partial \theta}=0
$$

holds.

Hence, for $\theta^{*}$, this gives the equation

$$
0+g \frac{\partial v}{\partial \theta}=0+r \frac{\partial v}{\partial \theta}=0+\theta^{*} \frac{\partial v}{\partial \theta}
$$

So long as capital value changes with marginal changes in production technique, i.e., so long as

$$
\frac{\partial v}{\partial \theta} \neq 0
$$

it follows from the above equation that

$$
\theta^{*}=g
$$

This is the Golden Rule of Accumulation. It thus holds far more generally than just in the Solow Growth Model in which it has been traditionally derived. The famous Golden Rule in the Solow Model is just a special case of this far more general Golden Rule.

The Golden Rule of Capital Accumulation holds whenever steady-state efficiency holds, the capital coefficient is constant over time in the steady state, and a marginal change in the production technique within the set Theta entails a change in the capital tied up in the production technique. 
In Sect. 2.10, we will discuss the case when steady-state efficiency does not hold. For this case, we can derive a modified Golden Rule of Accumulation, which we will also use further on in the book.

\subsection{The Public Debt Ratio and the Period of Production}

We now turn to the question of the effect of net public debt in the steady state. We first introduce the variable $\hat{w}$. Mathematically, it is defined as follows:

$$
\hat{w}(r ; \theta ; D)=w(r ; \theta)(1-(r-g) D)
$$

Here, $D$ is the steady-state public debt ratio. It is defined as the ratio of net public debt per labor year to the variable $w$. The expression $r w D$ thus represents the government's interest expenditure per labor year. The expression $g w D$ represents net borrowing per labor year, inasmuch as $D$ remains constant over time. The difference between these two variables is the fiscal "primary surplus" per labor year corresponding to a constant debt ratio $D$. If we consider that this primary surplus is generated by a tax on private households, then the economic interpretation of $\hat{w}$ is clear: It is the "remaining" income $w$ per labor year minus the government's tax-financed primary surplus. The remaining taxes and charges paid to the government are then exactly equal to remaining government expenditure, such that the private sector in this respect transfers exactly as much to the government as it receives from the government in payments.

We now consider a general equilibrium corresponding to zero public debt: i.e., with $D=0$. The rate of interest associated with this equilibrium is what we have defined as the natural rate. We will designate this interest rate by the Greek letter "rho," written $\rho$. We can now observe the following:

As a rule, $\hat{w}(r ; \theta(r) ; D)$ is different from $w(r ; \theta(r))$. At $r=g$ and at $r=\rho$, however, the primary surplus disappears, and therefore

$$
\widehat{w}(\rho ; \theta(\rho) ; 0)=w(\rho ; \theta(\rho)) \text { and } \widehat{w}\left(g ; \theta^{*} ; D\right)=w\left(g ; \theta^{*}\right)
$$

holds.

It will be useful now to consider the partial derivative of $w$ with respect to the steady-state rate of interest in somewhat greater detail. Purely formally, we first write

$$
\frac{\partial w}{\partial r}=-T w \text { or equivalently } \frac{\partial w / \partial r}{w}=-T
$$

A dimensional analysis of the variables involved shows that the variable $T$ has the dimension of time. We can as a rule assume that the "remaining" income decreases in the steady state, if the risk-free interest rate $r$ increases. Hence, $T$ is a 
positive length of time. What is the economic meaning of $T$ ? For the usual capital-theoretical models, we can show that $T$ represents the current average period of production, which in Böhm-Bawerk determines capital requirements per worker and which he used to formulate his "law of the greater productivity of more roundabout production." The period of production is the average time lag between employed labor hours and the point in time when the consumer goods produced with them become available. For the expression $T$ that we have introduced here to have this economic meaning, the labor inputs have to be weighed by their present values when calculating the average of this time lag. The average period of production defined in this way goes back to Hicks's Value and Capital (Hicks 1939).

Capital theorists traditionally only worked with labor as the original factor of production. The roots of this approach are to be found in the efforts of "bourgeois" economics to respond to Karl Marx's labor theory of value. It was only Samuelson's integration of Ricardian land rent into capital theory (Samuelson 1959a, b) that changed things somewhat. But even the famous Cambridge versus Cambridge capital debate was conducted without the factor of land. If we include scarce land in the capital-theoretical calculation, then the above-defined temporal expression $T$ has a different meaning than it does in Böhm-Bawerk. In Chap. 5 on land as a component of wealth, we will explicitly separate the period of production as such and a temporal expression for the capital value of future land rents. But here we combine both temporal expressions in the variable $T$. We, nonetheless, call $T$ the "period of production" in our verbal argument.

In the spirit of Böhm-Bawerk, we will now make a connection between the capital requirements of the production process and the average period of production. From the equation

$$
c(\theta)+g v(r ; \theta)=w(r ; \theta)+r v(r ; \theta)
$$

we can, for the case $r \neq g$, derive an equation for the capital requirements

$$
v(r ; \theta)=\frac{c(\theta)-w(r ; \theta)}{r-g}
$$

By L'Hôpital's rule, at $r=g$, we obtain the equation

$$
v(g ; \theta(g))=\frac{-\partial w / \partial r}{1}=w T=c T
$$

If $r=g$, then the capital required per labor year is equal to the product of the "annual wage" times the period of production or the product of consumption per labor year times the period of production. Böhm-Bawerk's intuition is thus justified precisely when the interest rate has the value at which steady-state consumption reaches its maximum. We call 


$$
v(g ; \theta(g))=w T=c T
$$

the "Böhm-Bawerk equation." To the best of our knowledge, it was first derived in the context of a capital-theoretical model in von Weizsäcker (1971).

\subsection{Private Wealth $T+D$}

Here again our definitional equation for $\hat{w}$.

$$
\hat{w}(r ; \theta ; D)=w(r ; \theta)(1-(r-g) D)
$$

Assumption 1 essentially means that $D(r)(r-\rho)>0$, so long as $r \neq \rho$.

We observe that for each $r$ in the middle range between $\rho$ and $g$, the inequality $\hat{w}$ $(r ; \theta(r) ; D)>w(r ; \theta(r))$ holds, while outside the interval between $\rho$ and $g$, on the contrary, $\hat{w}(r ; \theta(r) ; D)<w(r ; \theta(r))$ holds. This conclusion holds for both $\rho<g$ and $\rho>g$. If $\rho=g$, then the middle range drops out, but the inequality $D(r)(r-\rho)>0$ still holds, so long as $r \neq \rho$.

Now, let $\hat{v}$ be the wealth of private households per labor year. In what follows, we assume that all real capital is privately owned. In the steady state, an equation must hold for households that runs parallel to the equation that was already specified above for the production sector

$$
\widehat{c}+g \widehat{v}(r ; \theta(r)=\widehat{w}(r ; \theta(r) ; D(r))+r \widehat{v}(r ; \theta(r))
$$

Here, $\hat{c}$ is consumption per labor year, which has, of course, to be equal to the volume of consumer goods produced by the production sector per labor year. The left hand side divides household income per labor year into consumption and savings. The right hand side divides household income per labor year into risk-free interest on assets and other income. For $r \neq g$, we obtain the following equation for private wealth

$$
\widehat{v}(r ; \theta(r))=\frac{c(\theta(r))-\widehat{w}(r ; \theta(r))}{r-g}=v(r ; \theta(r))+w D(r)
$$

Accordingly, for $r=g$, we calculate

$$
\widehat{v}\left(g ; \theta^{*}\right)=w\left(g ; \theta^{*}\right)(T(g)+D(g))=c\left(\theta^{*}\right)(T(g)+D(g))
$$

Private wealth is greater than national wealth, if net public debt is positive. It is less than national wealth, if net public debt is negative. 


\subsection{The Golden Rule for the Lifetime Utility of the Representative Household}

Analogously to the period of production $T$ on the production side, we can introduce a waiting period $Z$ on the household side. It indicates the average time lag, expressed in present values, between performed labor and the consumption expenditure financed by it. The waiting period can also be negative: for example, if, in order to consume today, someone takes out a loan, which he or she will repay later from labor income. The normal case, however, is a positive $Z$. The situation of the household's wealth is tightly connected to the waiting period $Z$. We examine this matter in detail in Chap. 3 on desired wealth.

What interests us here is the waiting period in the steady state, since it is related to the Golden Rule of Accumulation. In parallel to the Phelps-Weizsäcker theorem on maximum steady-state consumption, there is also a theorem, which goes back to Samuelson (1958), on the optimal interest rate for the utility-maximizing distribution of consumption over the lifetime of the private household.

Like Samuelson did, we will use the idea of the representative household. Just as, for purposes of simplification, we did not distinguish between land rent and labor income in our discussion of the "period of production," so too in dealing with the waiting period, we will discuss the case in which no wealth is left as inheritance to the next generation. We go into the topic of inheritance in detail in Chap. 3 on desired wealth.

The Samuelson theorem on the optimal steady-state life plan for work and consumption can be formulated as follows. If, in a model with overlapping generations, we compare different steady states with different interest rates, we can ask how great, depending on the interest rate, average consumption per labor year must be, in order to obtain a specified level of lifetime utility $U$. As Samuelson shows using a simple example in his famous 1958 "overlapping generations" article, the required steady-state consumption per labor year for a specified level of utility is at a minimum when the interest rate is equal to the growth rate. We can derive this result in generalized form by making Assumption 4 of Steady-State Efficiency 2.

First, let us introduce a definition. Let $\operatorname{Eta}(U)$ be the set of all work-consumption patterns $\eta$ of the representative household that generate a lifetime utility level of $U$. Let $\bar{w}(\eta ; r)$ be the level of the "remaining income" that at a risk-free interest rate $r$ is just sufficient to finance the work and consumption pattern $\eta$. As above in the case of $\theta$, let $\eta(r)=r$ be the name of the work-consumption pattern that is realized in the steady state at an interest rate $r$ and at "remaining income" $\hat{w}=\mathrm{w}(r ; \theta(r))$ $(1-(r-g) D(r))$. We now consider the lifetime utility level $U(\eta(r))$.

Assumption 4 Steady-State Efficiency 2: For all $\eta \in \operatorname{Eta}(U)(\eta(r)), \hat{w}(\eta ; r) \geq$ $\overline{\mathrm{W}}(r ; \eta(r))$ holds. 
The economic meaning of this assumption is that the representative household maximizes its lifetime utility within the framework of the intertemporal budget that is given by $r$ and $\hat{w}(r)$.

We now consider the consumption per labor year that results from a hypothetical steady state in which the interest rate $r=g$ and the work-consumption pattern $\eta \in$ $\operatorname{Eta}(U(\eta(g))$ is realized. Here, $\bar{w}(\eta ; g)=\bar{c}(\eta)$ holds, whereby $\bar{c}(\eta)$ is the consumption per labor year corresponding to the work-consumption pattern $\eta$ in the steady state. Hence, on account of Steady-State Efficiency 2, the following holds:

$$
\bar{c}(\eta)=\bar{w}(\eta ; g) \geq \hat{w}(g ; \eta(g))=w\left(g ; \theta^{*}\right)=c\left(\theta^{*}\right)
$$

In conjunction with the Golden Rule of Accumulation, this inequality shows that the steady-state lifetime utility of the representative household is maximized at an interest rate of $r=g$. We have thus derived:

The Golden Rule for the Lifetime Utility of the Representative Household In comparing different steady states, the lifetime utility of the representative household is maximized when the equilibrium rate of interest is equal to the growth rate: $r=g$.

On this proposition see also Weizsäcker (2021, Chap. 2, Sect. 2).

As already mentioned above, this Golden Rule for Lifetime Utility was already demonstrated by Samuelson in 1958 for a special case. In the model he used at the time, the production process did not need any capital. Thus, Samuelson left other economists the opportunity to discover the Phelps-Weizsäcker Golden Rule of Accumulation.

\subsection{At the Optimum, the Overall Economic Period of Production $=$ The Overall Economic Waiting Period}

We now return to the waiting period $Z$. For every given work-consumption pattern $\eta$, it can be shown that:

$$
\frac{\partial \bar{w}(\eta ; r)}{\partial r}=-Z(\eta ; r) \bar{w}(\eta ; r)
$$

Let us introduce the indirect lifetime utility function $U(r ; \hat{w})$. From the above equation, 


$$
\frac{\partial U}{\partial r}=\frac{\partial U}{\partial \bar{w}} Z \hat{w}
$$

follows for its partial derivatives.

For, of course, lifetime utility does not change, if a marginal increase in the interest rate is accompanied by a reduction in the wage, which just makes it possible to finance the hitherto existing work-consumption pattern.

Moreover, we can grasp lifetime utility as a function of the respective steady-state rate of interest. This results in

$$
\frac{d U}{d r}=\frac{\partial U}{\partial r}+\frac{\partial U}{\partial \widehat{w}} \frac{d \widehat{w}}{d r}=\frac{\partial U}{\partial r}+\frac{\partial U}{\partial \widehat{w}}\left\{-T w(1-(r-g) D)-w D-w(r-g) \frac{d D}{d r}\right\}
$$

Since steady-state utility is maximized at $r=g$, it follows that at $r=g$,

$$
\frac{\partial U}{\partial r}+\frac{\partial U}{\partial \hat{w}}\{-w(T+D)\}=0
$$

holds.

From this equation and the above equation

$$
\frac{\partial U}{\partial r}=\frac{\partial U}{\partial \bar{w}} Z \hat{w}
$$

for $r=g$, we deduce the equation (remembering $\widehat{w}=w$ at $r=g$ )

$$
T(g)+D(g)=Z(g)
$$

This can be expressed as follows: The sum of the private waiting period $Z$ and the public waiting period $-D$ is, so to say, the "waiting period" of the economy as a whole or the overall economic waiting period. In the steady-state optimum, the overall economic waiting period $Z-D$ is thus equal to the overall economic period of production $T$. Steady-state lifetime utility is thus maximized when the overall economic waiting period is equal to the overall economic period of production. We call the related equation

$$
T=Z-D
$$

the Fundamental Equation of Steady-State Capital Theory.

We established that the inequality $D(r)(r-\rho)>0$ holds for every rate of interest other than the natural rate $\rho$. In conjunction with the equation that we just derived for $r=g$, this shows us that the natural rate of interest is smaller than $g$ precisely when, at a rate of interest $r=g$, the private waiting period is greater than the period of production. 


\subsection{Deviations from the Steady State: The Interest Rate as Price Signal and the Risk Premium}

We are not analyzing the properties of steady states because we believe that the latter correspond to reality. Steady states are not a matter of art for art's sake. In the natural sciences as well, hypothetical steady states are studied, in order to understand the mechanics of a system in motion. As Keynes wrote in The General Theory, on his view, "the system...whilst it is subject to severe fluctuations... it is not violently unstable" (Keynes 1936, p. 249). The overwhelming majority of economists are of the opinion that it makes sense to study hypothetical steady states, in order to understand the dynamics of the economy as a whole. It is not our intention here to undertake any comprehensive dynamic analysis, which nowadays is sometimes done using highly complex macro models. Our purpose is merely to introduce certain concepts from stochastic dynamics that we also want to use for steady-state analysis. For the properties of a social steady state are, of course, also influenced by the fact that there can be deviations from this steady state. If, for instance, we consider a condition of balance of power between rival nations, such "peaceful co-existence" will normally be a condition of armed peace. The nations involved will devote a considerable part of their national product to armaments expenditures, even though the armaments are not currently being used.

We are especially interested in two things that are only to be encountered outside of the steady state: 1 . The exact significance of the internal rate of return on a current foregoing of consumption - to which we already referred above; and 2. the fact that saving and investment activities are always associated with risk.

In his book Capital Theory and the Rate of Return, the founder of the neoclassical theory of growth, Robert Solow, described how models can be developed in which the prevailing interest rate is a price signal for the ratio of a current foregoing of consumption to additional future consumption that is made possible by it (Solow 1964). We assume, for example, that the economy is in a steady state corresponding to a given rate of interest $r$. Now, we modulate the consumption path of the economy by a small (marginal) change $\varepsilon \Delta c(t)$, such that, at the beginning, $\Delta c(0)<0$ (= current foregoing of consumption), later, however, it is positive for a while, in order then, starting at some finite point in time $E>0$, to be zero again. Let us use $r^{*}$ to designate the internal rate of return of this small deviation from the steady state consumption path. Hence, this is the rate for which the following equation holds:

$$
\int_{0}^{E} e^{-r^{*} t} \varepsilon \Delta c(t) d t=0
$$

As long as the steady-state rate of interest $r$ is an unbiased price signal for the internal rate of return $r^{*}$, the inequality $r^{*} \leq r$ holds. We can, moreover, construct a corresponding deviation path for every $\varepsilon$-and then grasp $r^{*}$ as a function of $\varepsilon$ : 
that is, $r^{*}(\varepsilon)$. If the rate of interest $r$ is an unbiased price signal, then $r^{*}$ reaches its maximum at $\varepsilon=0$ and

$$
r^{*}(0)=r
$$

holds.

It should be explicitly noted that this equation also holds if $r<g$ : that is, if "dynamic inefficiency" is present. The reason is that in this thought experiment, we return to the steady-state path with its associated capital endowment at a finite point in time $E$. Dynamic inefficiency stems, after all, from the fact that at $r<g$, one can forego the steady-state growth of the capital endowment and, from then on, always work with a lesser capital stock than on the steady-state path. In the Solow-TobinWeizsäcker-Yaari paper from 1966, the authors showed that the interest rate as price signal is also unbiased in a standard "vintage" model (Solow et al. 1966).

Assumption 2 only relates to the comparison of production techniques that are employed in some steady state (the set Theta). It can be shown that if the interest rate is also a correct price signal outside of steady states, then Assumption 2 also holds. The converse is not the case.

The steady state that we have presented thus far does not have any risk component. But in every economy, there is also, of course, macroeconomically relevant risk. Since public debt is the focus of our book, our analysis has also to include the risk borne by owners of government bonds and other government liabilities. We will go into some of the various forms of government liabilities, in particular, in Chap. 6: the chapter dealing with public debt.

In Germany or in the USA, there are government bonds that are regarded on the capital market as having a default risk of zero. They can thus serve as a "benchmark," in order to calculate a risk premium on the government bonds of other countries. The risk premium is, for instance, the additional return on a bond as compared to the return on German government bonds. In this book, we will use the Greek letter "alpha"- $\alpha-$ to designate this risk premium. Such a risk premium also exists in the case of real assets: like real capital and land. For these risk premiums, we also use the symbol $\alpha$.

\subsection{What if the Interest Rate Represents a Biased Price Signal?}

The Golden Rule of Accumulation and the Golden Rule for Lifetime Utility were derived above on the assumption of the steady-state efficiency of both the production system (Assumption 2) and the domain of consumption (Assumption 4). The rate of interest at which the optimality condition $r=g$ holds is, then, the riskfree rate of interest at which the government can borrow. In this section, we replace these two assumptions by a more general framework, such that the assumptions that we have hitherto made are merely special cases. In this more general framework, the Golden Rules of accumulation and of lifetime utility no longer hold in their 
previous form. The new "Golden Rule" is somewhat more complicated than the prior ones. Nonetheless, the variable $r$ retains its prior meaning: It is still the risk-free rate of interest at which the government can borrow.

One motivation for this generalization is the criticism of the monetary policy of the ECB that is often heard in Germany. The ECB is often accused of distorting the interest rate downwards by way of an expansionary monetary policy. Thus, the market rates are alleged to be lower than the interest rate corresponding to full-employment equilibrium in the real economy. Another way of formulating this is that due to ECB policy, the interest rate has fallen to a level that is lower than the internal rate of return on currently foregoing consumption in favor of increased future consumption. In the spirit of this critical motivation, the reader may conceive the bias parameter $\beta_{1}$ to be introduced momentarily as positive. Nonetheless, the formal apparatus we are introducing also works with negative bias parameters. We are carrying out this analysis, because it shows that our approach does not depend on the assumption that the rate of interest $r$ is a correct price signal in both the production sector and the consumption sector.

We now introduce a bias parameter $\beta_{1}$ for the production sector. In order to use it rationally for modeling purposes, we first need, in purely formal terms, to redefine our variable $w$. We define it as follows:

$$
w(r ; \theta)=y-\left(r+\beta_{1}\right) v(r ; \theta)
$$

The variable $w$ is thus the surplus of the total product per labor year above $\left(r+\beta_{1}\right)$-times the capital employed. The expression $\left(r+\beta_{1}\right)$ is the internal rate of return on a deviation from the steady state by way of a small (infinitesimal) current foregoing of consumption in favor of additional future consumption, like we presented in the last section. Without a price signal bias, this internal rate of return would be exactly equal to $r$. The bias parameter is thus the exact difference between what the interest rate should be signaling and its actual value.

To the extent that there is no bias $\left(\beta_{1}=0\right), w$ also stands for the flow of all other income: i.e., all income apart from risk-free capital income. If $\beta_{1}$ is positive, then the risk-free capital income per unit of capital is less than the internal rate of return on a current marginal foregoing of consumption. Accordingly, at macroeconomically constant returns to scale, the income of all factors of production apart from capital is greater than the combined "marginal product" of all factors of production apart from capital. Conversely, if $\beta_{1}$ is negative, at macroeconomically constant returns to scale, the income of all factors of production apart from capital is less than the combined "marginal product" of all factors of production apart from capital. At macroeconomically constant returns to scale, the modified expression $w$ $(r ; \theta)=y-\left(r+\beta_{1}\right) v(r ; \theta)$ represents the combined "marginal product" of all factors of production apart from capital.

Using this generalized definition of the surplus $w$, we now introduce the following assumption, which gives expression to the price-signal bias of the interest rate: 
Assumption 2-Beta For every rate of interest $r$ and all $\theta \in$ Theta, $w(r$; $\left.\theta\left(r+\beta_{1}\right)\right) \geq w(r ; \theta)$ holds.

This assumption means that the price signal $r$ is biased precisely in the sense that the "marginal productivity of capital" is $\beta_{1}$ greater than the interest rate $r$. If $\beta_{1}=2 \%$ per year, then an interest rate of $0 \%$, for example, signals that a production technique is being used that would correspond to an interest rate of $2 \%$ per year without bias.

If $\varphi$ is the marginal product of capital and we give the production technique $\theta(\varphi)$ the name $\varphi$, then the equation

$$
\frac{\partial w\left(r ; \theta\left(r+\beta_{1}\right)\right)}{\partial \theta}=0
$$

follows from our Assumption 2-Beta.

Let us again consider the equation

$$
c(\theta)+g v(r ; \theta)=w(r ; \theta)+\left(r+\beta_{1}\right) v(r ; \theta)
$$

By way of partial differentiation with respect to $\theta$, we have then in general

$$
\frac{d c}{d \theta}+g \frac{\partial v(r ; \theta)}{\partial \theta}=\frac{\partial w}{\partial \theta}+\left(r+\beta_{1}\right) \frac{\partial v(r ; \theta)}{\partial \theta}
$$

From this, we can calculate, in an analogous manner to our procedure in Sect. 2.4, that the marginal productivity of capital is given by the equation

$$
\varphi=r+\beta_{1}
$$

Let $\theta^{*}$ be the steady state production technique from the set Theta that maximizes consumption per labor year in the steady state. Let there be only one such $\theta^{*}$. It is only here, then, that we obtain the result

$$
\frac{d c}{d \theta}=0
$$

Moreover, due to Assumption 2-Beta, at $\theta=\left(r+\beta_{1}\right)$, the partial derivative is

$$
\frac{\partial w}{\partial \theta}=0
$$

Thus, for $\theta=\left(r+\beta_{1}\right)$, we obtain the equation 


$$
\frac{d c}{d \theta}+g \frac{\partial v(r ; \theta)}{\partial \theta}=0+\left(r+\beta_{1}\right) \frac{\partial v(r ; \theta)}{\partial \theta}
$$

We assume that

$$
\frac{\partial v(r ; \theta)}{\partial \theta} \neq 0
$$

For $r+\beta_{1}=g$, this gives

$$
\frac{d c}{d \theta}=0
$$

And for every value $r+\beta_{1} \neq g$,

$$
\frac{d c}{d \theta} \neq 0
$$

holds.

The optimal steady-state rate of interest for the maximization of steady-state consumption per labor year is thus given by the equation

$$
r=g-\beta_{1}
$$

For this optimum, moreover, we can note that

$$
w=c\left(\theta^{*}\right)+g v\left(g-\beta_{1} ; \theta^{*}\right)-g v\left(g-\beta_{1} ; \theta^{*}\right)=c\left(\theta^{*}\right)
$$

Thus, in the steady state optimum, the combined "marginal product" of all factors of production apart from capital is equal to consumption in the economy as whole-so long as there are macroeconomically constant returns to scale.

If we are interested in the maximization of the lifetime utility $U$ of the representative household, then we also have to take into account the interest rate as a price signal in the consumption sector. In Sect. 4.1 .5 of Chap. 4 on real capital, we propose the introduction of a coefficient of intertemporal substitution. The latter can be defined for both the production sector and the consumption sector. We call it $\psi$ for the production sector and $\gamma$ for the consumption sector. Drawing on Weizsäcker (2021), we show in Sect. 4.1.6 that the percentage loss in welfare $\Omega$ brought about by a deviation of the empirical interest rate from its lifetime utility-maximizing value $g$ can be roughly calculated using the formula

$$
\Omega=\left(\psi T^{2}+\gamma Z^{2}\right)(r-g)^{2} / 2 .
$$

This formula holds, if the rate of interest is a correct price signal in both the production sector and the consumption sector, since in that case, the optimal rate of interest is the same in both sectors: namely, $g$. 
In Weizsäcker (2021), we demonstrate an approximation formula for the optimal compromise between the sector-optimal rate of interest $r=g-\beta_{1}$ in the production sector and the sector-optimal rate of interest $r=g$ in the consumption sector. It is assumed here that the interest rate represents a correct price signal for intertemporal consumption decisions.

We can arrive at a good approximation of the optimal compromise $r^{*}$ between the rate of interest $r=g-\beta_{1}$ and the rate of interest $r=g$ by using the following formula

$$
r^{*}=\frac{\psi T^{2}}{\psi T^{2}+\gamma Z^{2}}\left(g-\beta_{1}\right)+\frac{\gamma Z^{2}}{\psi T^{2}+\gamma Z^{2}} g .
$$

$r^{*}$ is thus a weighted average of $g-\beta_{1}$ and $g$, whereby the weights correspond to the percentage contributions of the respective sectors to the overall percentage loss $\Omega$ that results, provided the sectoral rates are correct price signals on both sides, when the rate of interest $r$ deviates from its optimal value $g$.

On our empirical estimate, the "waiting period" $Z$ is at least double the period of production $T$. Moreover, the coefficient of intertemporal substitution $\gamma$ is at least equal to $\psi$. Since $T$ and $Z$ enter into the weighting formula for $r^{*}$ with their squares, the weight of $g$, even at $\psi=\gamma$ and a value of $Z=2 T$, would be approximately four times greater than the weight of $g-\beta_{1}$. Hence, the optimal compromise rate of interest $r^{*}$ is considerably closer to $g$ than to $g-\beta_{1}$. At $\psi=\gamma$ and $Z=2 T$, we get the equation

$$
r^{*}=\frac{1}{5}\left(g-\beta_{1}\right)+\frac{4}{5} g .
$$

\subsection{Calibrating Welfare Losses for $r \neq g$ : An Example}

In Chap. 3, Sect. 3.9 of Weizsäcker (2021) we have given a calibration of the steady state loss in welfare that would occur if one pursued a policy of zero public debt. The maximum welfare is achieved at a rate of interest equal to the rate of growth, as we have shown above. Using the approximation formula for welfare loss

$$
\Omega=\left(\psi T^{2}+\gamma Z^{2}\right)(r-g)^{2} / 2
$$

and using the empirical results later to be described in the present volume (Chaps. 4, 5 , and 6), we have developed methods to obtain estimates of the parameters of this equation. We assume the natural rate of interest to be $\rho=-2 \%$ per year. This is not really an estimate, because we believe that it is impossible to know how far into the negative the natural rate will plunge. Saving and investment behavior changes completely once people are faced with substantial inflation and still a zero nominal rate of interest. Thus $\rho$ may in fact be far below $-2 \%$ per year.

At a steady-state rate of growth of $3 \%$ per year for the OECD + China region, we then can work with a difference between $g$ and $\rho$ of 5\% per year. Using our 
empirical work, we have the following values at $r=g$ : 10 years for the waiting period and 4 years for the period of production. Using the Solow production function and the fact that the capital-output ratio does not exhibit any trend over more than a century leads us to the conclusion that $\psi$ has a value of approximately 1. The established empirical work on intertemporal substitution in the consumption sector allows us to derive the inequality $\gamma \geq \psi$. To be on the safe side, we assume $\gamma=\psi=1$. In that case, the value of $\Omega$ would be $29 \%$.

If we assume $\gamma=1.5$ instead, we obtain a value $\Omega=41.5 \%$.

This estimate of the percentage welfare loss at an annual real rate of interest of $-2 \%$ ignores the additional problem that it would then be much more difficult to obtain and maintain full employment: The central bank cannot overcome the Keynesian liquidity trap.

\subsection{Conclusion}

In this chapter, we have shown that by using a steady-state analysis, we can work out connections between saving and investment that can help us to understand secular trends in the natural rate of interest. We have tried here to get by with just a few assumptions representing sufficient conditions for the derived "Golden Rules." It has proven to be fruitful to relate private saving to the "waiting period" $Z$ and to relate investment to Böhm-Bawerk's period of production as modernized by Hicks or $T$. We have just given an example of what occurs if we deviate from the assumption that the risk-free interest rate $r$ is a correct price signal for intertemporal production decisions (investment decisions). We will discuss further deviations from the assumptions of the steady-state model in subsequent chapters. For the purpose of understanding public debt, it is interesting to note that the steady-state optimum $(r=g$ ) entails the equality of the overall economic waiting period $Z-D$ and the overall economic period of production $T$. Generalizing findings of Diamond (1965), we can say that public debt serves here to bring about this equality. The following is also of interest: Since the natural rate of interest $\rho$ is nowadays far lower than the growth rate, Samuelson's Golden Rule is far more important in quantitative terms than the Phelps-Weizsäcker Golden Rule. It is a mistake that Samuelson's Golden Rule is hardly taken into account in contemporary economic theory.

\section{References}

Abel, Andrew B., N. Gregory Mankiw, Lawrence Summers and Richard Zeckhauser.1989. Assessing Dynamic Efficiency: Theory and Evidence. Review of Economic Studies 56 (1): 1-19.

Böhm-Bawerk, Eugen Ritter von. 1891 [1889]. The Positive Theory of Capital, trans. William Smart. London and New York: Macmillan.

Diamond, Peter A. 1965. National Debt in a Neoclassical Growth Model. American Economic Review 55 (5): 1126-1150.

Geerolf, Francois. 2018. Reassessing Dynamic Efficiency. Manuscript UCLA.

Hicks, John R. 1939. Value and Capital. Oxford: Clarendon Press. 
Keynes, John Maynard. 1936. The General Theory of Employment, Interest and Money. London: Macmillan.

Marx, Karl. 1976 [1867]. Capital: A Critique of Political Economy, vol. 1, trans. Ben Fowkes. London: Penguin/New Left Books.

Phelps, Edmund S. 1961. The Golden Rule of Capital Accumulation. American Economic Review 51 (4): 638-643.

Rachel, Lukasz and Lawrence H. Summers. 2019. On Falling Neutral Real Rates, Fiscal Policy, and the Risk of Secular Stagnation. Brookings Papers on Economic Activity March 4: 1-66.

Samuelson, Paul A. 1958. An Exact Consumption-Loan Model of Interest with or without the Social Contrivance of Money. Journal of Political Economy 66 (6): 467-482.

Samuelson, Paul A. 1959a. A Modern Treatment of the Ricardian Economy I: The Pricing of Goods and of Labor and Land Services. Quarterly Journal of Economics 73 (1): 1-35.

Samuelson, Paul A. 1959b. A Modern Treatment of the Ricardian Economy II: Capital and Interest Aspects of the Pricing Process. Quarterly Journal of Economics 73 (2): 217-231.

Schnabl, Gunther. 2019. Central Banking and Crisis Management from the Perspective of Austrian Business Cycle Theory. In The Oxford Handbook of the Economics of Central Banking 2019, eds. David G. Mayes, Pierre L. Siklos and Jan-Egbert Sturm, 551-584. Oxford: Oxford University Press.

Schumpeter, Joseph. A. 1934 [1911]. The Theory of Economic Development, trans. Redvers Opie. Cambridge, MA: Harvard University Press.

Solow, Robert M. 1956. A Contribution to the Theory of Economic Growth. Quarterly Journal of Economics 70 (1): 65-94.

Solow, Robert M. 1957. Technical Change and the Aggregate Production Function. Review of Economics and Statistics 39 (3): 312-320.

Solow, Robert M. 1963. Capital Theory and the Rate of Return. De Vries Lectures. Amsterdam: North-Holland.

Solow, Robert M., James Tobin, Carl Christian von Weizsäcker und Menahem Yaari. 1966. Neoclassical Growth with Fixed Factor Proportions. Review of Economic Studies XXXIII (2): 79-115.

Weizsäcker, Carl Christian von. 1961. Wachstum, Zins und optimale Investitionsquote. Dissertation, Universität Basel. Published as: Weizsäcker, Carl Christian von. 1962. Wachstum, Zins und optimale Investitionsquote. Tübingen: Mohr-Siebeck.

Weizsäcker, Carl Christian von. 1971. Steady State Capital Theory. Heidelberg: Springer.

Weizsäcker, Carl Christian von. 2021. Capital Theory of the Steady State - Or: $T+L=Z-D$. https://www.coll.mpg.de/Weizsaecker/CapitalTheory2021 and https://www.springer. com/ 9783658273620 .

Wicksell, Knut. 1936 [1898]. Interest and Prices: A Study of the Causes Regulating the Value of Money, trans. R. F. Kahn. London: Macmillan.

Yared, Pierre. 2019. Rising Government Debt: Causes and Solutions for a Decades Old Trend. Journal of Economic Perspectives 33 (2): 115-140.

Open Access This chapter is licensed under the terms of the Creative Commons Attribution 4.0 International License (http://creativecommons.org/licenses/by/4.0/), which permits use, sharing, adaptation, distribution and reproduction in any medium or format, as long as you give appropriate credit to the original author(s) and the source, provide a link to the Creative Commons license and indicate if changes were made.

The images or other third party material in this chapter are included in the chapter's Creative Commons license, unless indicated otherwise in a credit line to the material. If material is not included in the chapter's Creative Commons license and your intended use is not permitted by statutory regulation or exceeds the permitted use, you will need to obtain permission directly from the copyright holder.

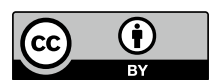

